\title{
On the effect of boron on the mechanical properties of a new polycrystalline superalloy
}

\author{
Paraskevas Kontis ${ }^{\mathrm{a}}$, Hanis A. Mohd Yusof, Katie L. Moore, Chris R.M. Grovenor, and Roger C. Reed \\ University of Oxford, Department of Materials, OX1 3PH Oxford, UK
}

\begin{abstract}
Boron is used as a grain boundary strengthener in the nickel-based superalloys, but the reasons for its effect and the optimum quantities which need to be added are not well understood. Recently, some of the authors have developed a new corrosion-resistant single crystal superalloy for power generation applications which has a good balance of mechanical properties and resistance to environmental degradation. Here, this same alloy system is studied but in the polycrystalline state with additions of boron and carbon. The influence of boron on creep behaviour has been quantified and rationalised, with an emphasis on the grain boundary phase transformations which occur. NanoSIMS is utilised to investigate the segregation of boron at grain boundaries, with SEM used to characterise the effect of boron on the precipitation of $\mathrm{Cr}_{23} \mathrm{C}_{6}$ type carbides at grain boundaries. When the boron content increases, the agglomeration of $\mathrm{M}_{23} \mathrm{C}_{6}$ carbides at grain boundaries is inhibited. Uniformly distributed discrete $\mathrm{M}_{23} \mathrm{C}_{6}$ carbides are observed at higher boron content, whereas a deleterious film of $\mathrm{M}_{23} \mathrm{C}_{6}$ along the grain boundaries arises as the boron concentration is reduced. Boron promotes also the formation of $\gamma^{\prime}$ layers at the grain boundaries.
\end{abstract}

\section{Introduction}

Nickel-based superalloys play a pivotal role in the performance of industrial gas turbines (IGTs). Over the last few decades, many improvements have been made to their microstructure and as a consequence in many instances conventional casting has been replaced by directional casting and in many cases by single crystal superalloys. However, polycrystalline superalloys are still utilized effectively as components on hot sections of IGTs, such as guide vanes, where single crystal alloys cannot be cast due to their complicated geometries. Therefore, grainboundary strengthening is often needed in these materials.

Boron, along with carbon, is known to promote grain boundary strengthening, and it is the focus of this paper. However, the mechanism through which boron improves the grain boundary strengthening of conventional cast superalloys remains highly controversial. Various strengthening mechanisms were proposed; among them the most popular include the increase of boundary interfacial energy [1,2] and the improvement of the grain boundary cohesive strength. Moreover, it has been suggested that the segregation of boron at grain boundaries may fill vacancies residing there, thereby the grain boundary diffusivity can decrease. As a consequence, as the diffusivity at the grain boundaries decreases, the rate of void formation decreases. Simultaneously the occurrence of $\gamma^{\prime}$ denuded zones is retarded, so that the creep properties are improved [1].

${ }^{a}$ Corresponding author: paraskevas . kontis@materials . ox . ac.uk
Besides these mechanisms, it was proposed that minor additions of boron are advantageous on creep life and ductility by decreasing the agglomeration of $\mathrm{M}_{23} \mathrm{C}_{6}$ carbides at the grain boundaries during protracted service exposures or heat treatment processes $[1,3-6]$. It is well known that a continuous layer of $\mathrm{M}_{23} \mathrm{C}_{6}$ along the grain boundaries serves as a crack initiation site, since stresses concentrate there. Thereby, strain on the slip planes is impeded by this layer to move from one grain to the vicinal grain and accordingly, stress-relief cannot be achieved [7].

This article is concerned with the relationship between the grain boundary character and mechanical properties, particularly in creep, of a new polycrystalline nickel-based superalloy. The effect of boron on the precipitation of $\mathrm{M}_{23} \mathrm{C}_{6}$ carbides at grain boundaries and its influence on creep resistance was studied.

\section{Experimental procedures}

The prototype nickel-based polycrystalline superalloy STAL-15CC investigated in this study has composition Ni5Co-15Cr-1Mo-3.5W-4.5Al-8Ta-0.1Hf-0.1C (wt-\%). In order to investigate the effect of boron on the mechanical properties, test-bars were cast containing various amounts of boron. In particular, test-bars with no boron (boron free-BF), low boron (LB - $0.006 \mathrm{wt}-\%$ ) and relatively higher boron (HB - 0.016 wt- $\%$ ) content were produced. Castings in the form of tapered rods (Fig. 1) were prepared at Doncasters Precision Castings Ltd., using casting stock melted by Ross \& Catherall (Sheffield, United Kingdom). Ceramic moulds were used, which had been prepared from alumina, silica and zircon in the usual way. In addition,

This is an Open Access article distributed under the terms of the Creative Commons Attribution License 4.0, which permits unrestricted use, distribution, and reproduction in any medium, provided the original work is properly cited. 

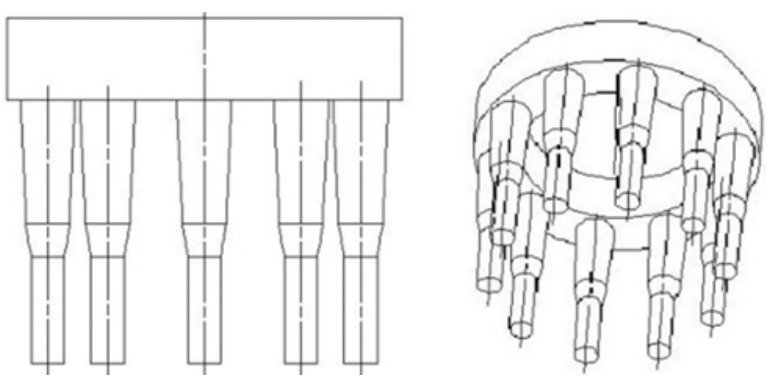

Figure 1. The mould geometry used in this work.

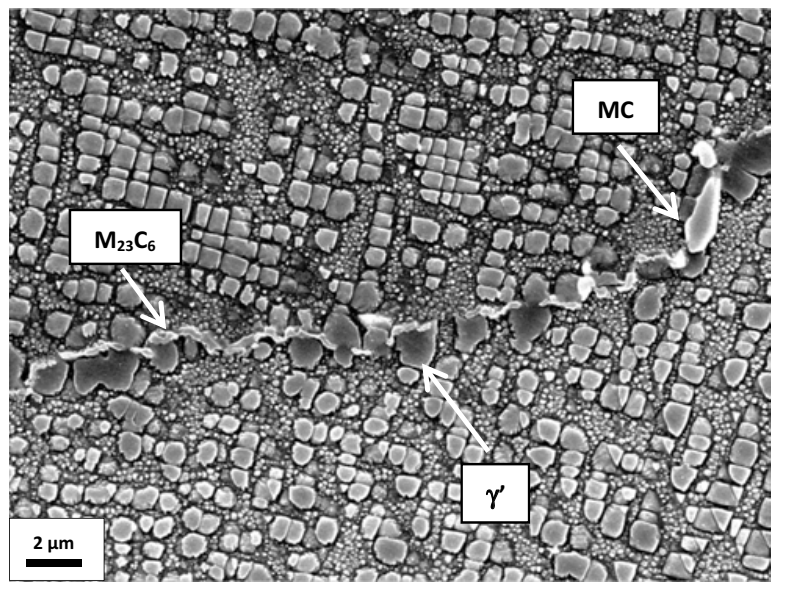

Figure 2. SEM image showing the fully heat treated microstructure of the BF specimen.

cobalt aluminate was utilized in the primary slurry as nucleation catalyst, in order to achieve a desirable grain size.

\subsection{Heat treatment}

After conventional casting (CC) the test-bars were hot isostatically pressed (HIP) at $1195^{\circ} \mathrm{C}$ for 5 hours under $175 \mathrm{MPa}$ pressure. Thermodynamic calculations using Thermocalc coupled with the TTNI7 database indicated a $\gamma^{\prime}$ solvus temperature of $1148^{\circ} \mathrm{C}$ and a solidus temperature of $1233^{\circ} \mathrm{C}$. The process of HIP was followed by a stage of primary ageing at $1120^{\circ} \mathrm{C}$ for 4 hours and a subsequent second stage of ageing at $845^{\circ} \mathrm{C}$ for 24 hours. Careful examination of the final heat treated microstructures revealed that the precipitated carbides at the grain boundaries exhibit different morphologies depending on the boron level.

In particular, both the $\mathrm{BF}$ and $\mathrm{LB}$ alloys exhibit a more or less continuous layer of $\mathrm{M}_{23} \mathrm{C}_{6}$ type along the grain boundaries, resulting from the degeneration of the MCtype carbides. Moreover, the breakdown of MC carbide results in larger, irregular $\gamma^{\prime}$ particles at the grain boundaries, as illustrated in Figs. 2 and 3. It was found that the size of the $\gamma^{\prime}$ particles at the grain boundaries differs between the $\mathrm{BF}$ and the LB alloy. It was observed that in the LB alloy the $\gamma^{\prime}$ particles exhibit a relatively larger size than that of the boron free one.

As boron increases, the precipitation of smaller blocky $\mathrm{M}_{23} \mathrm{C}_{6}$ carbides at the grain boundaries is promoted (HB specimen); these carbides are enveloped within

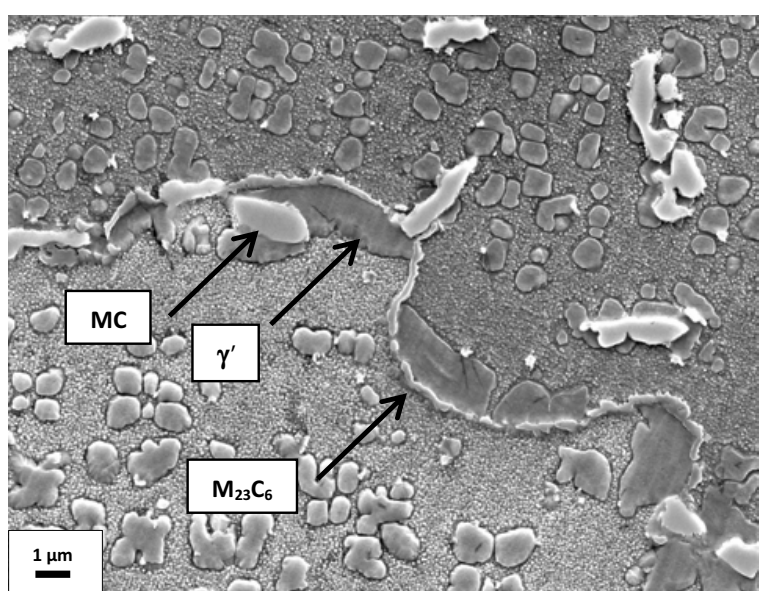

Figure 3. SEM image showing the fully heat treated microstructure of the LB specimen.

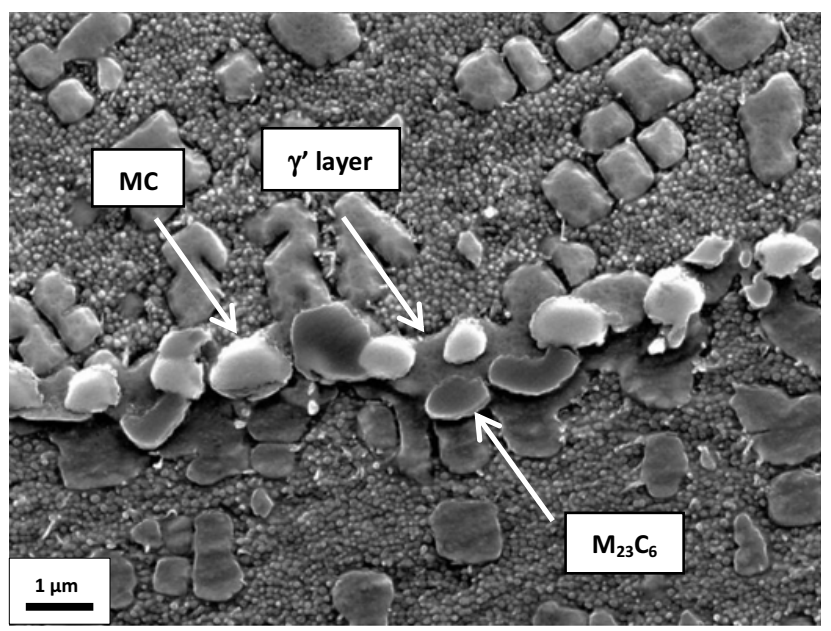

Figure 4. SEM image showing the fully heat treated microstructure of the HB specimen.

a continuous $\gamma^{\prime}$ layer at the grain boundaries. It is believed that this complex structure at the grain boundaries can improve the mechanical properties. The hard grain boundary carbides enveloped within the ductile $\gamma^{\prime}$ layers retard the crack initiation and thereby improve the rupture life and creep ductility at high temperatures [8]. Morphologies of the $\mathrm{MC}$ carbide, after its decomposition, and the precipitated $\mathrm{M}_{23} \mathrm{C}_{6}$ carbides enveloped within a $\gamma^{\prime}$ layer are illustrated in Fig. 4.

\section{Experimental results}

\subsection{Segregation of carbon and boron}

NanoSIMS analysis was carried out on fully heat treated samples with a CAMECA NanoSIMS 50. The samples were polished to attain flat surfaces. A $16 \mathrm{keV} \mathrm{Cs}^{+}$primary ion beam was used to sputter ions from each surface analysed. Prior to each measurement, the surface was cleaned with a high-energy primary ion beam.

The detectors were aligned to detect the ion species ${ }^{12} \mathrm{C}^{-},{ }^{11} \mathrm{~B}^{12} \mathrm{C}^{-},{ }^{11} \mathrm{~B}^{16} \mathrm{O}_{2}^{-}$and ${ }^{52} \mathrm{Cr}^{16} \mathrm{O}^{-}$. The ${ }^{11} \mathrm{~B}^{16} \mathrm{O}_{2}^{-}$ signal was chosen in preference to the ${ }^{11} \mathrm{~B}^{-}$and 


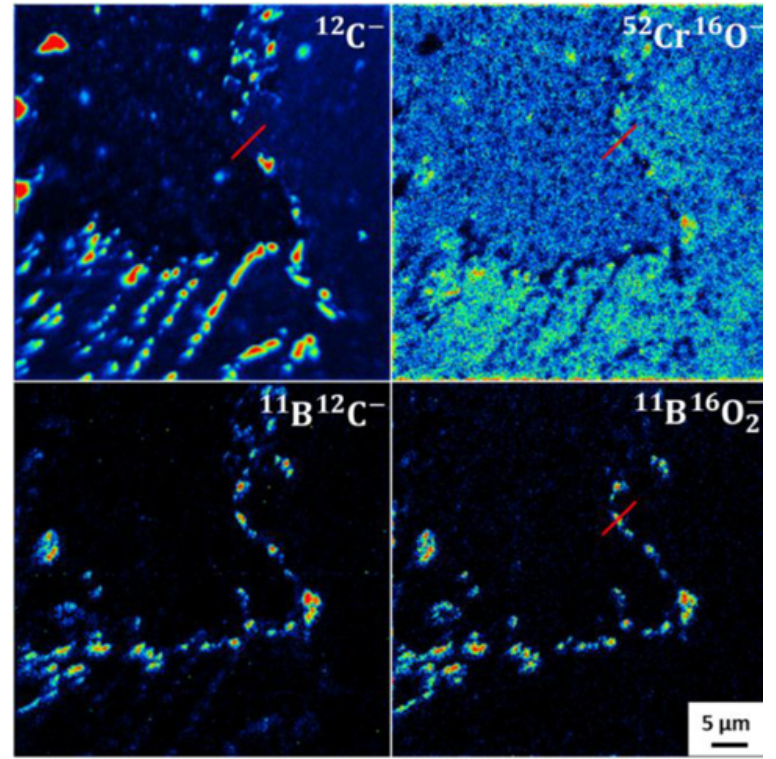

Figure 5. NanoSIMS images showing segregation of B and C at grain boundaries in a fully heat treated HB specimen, prior to creep test.

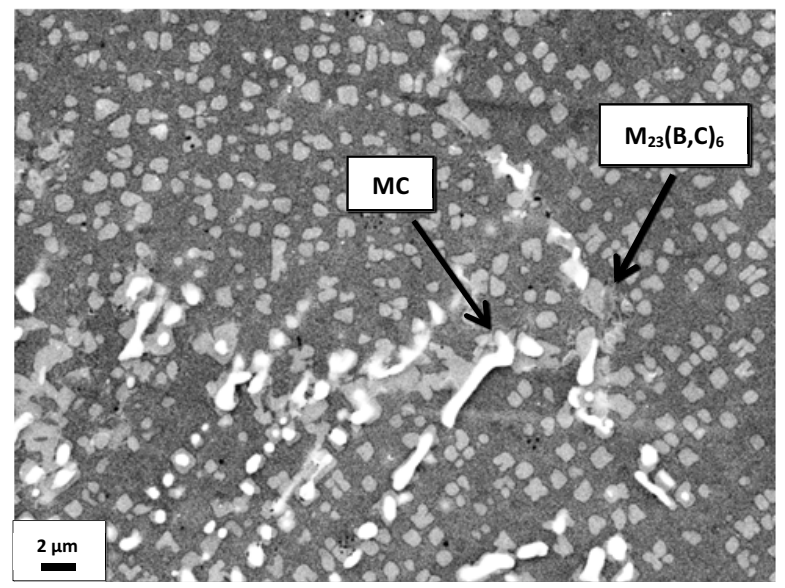

Figure 6. SEM image showing the analysed area by NanoSIMS of the HB specimen.

the ${ }^{11} \mathrm{~B}^{16} \mathrm{O}^{-}$signals because it gives a highest signal intensity [9]. Image processing was carried out using ImageJ software (U.S. National Institutes of Health, Bethesda, MD) using the OpenMIMS plugin (National Resource for Imaging Mass Spectometry, Harvard University, Cambridge, MA).

NanoSIMS analysis was carried out for the low and high boron specimens. The segregation of boron and carbon to the grain boundaries was revealed in the high and low boron specimens as illustrated in Figs. 5 and 7 , respectively. SEM images of the investigated areas of the high and low boron specimens after the NanoSIMS analysis are depicted in Figs. 6 and 8.

In particular, carbon was found to segregate both to grain boundaries, forming blocky MC-type carbides, and to grain interior where script-like $\mathrm{MC}$ carbides form. $\mathrm{Cr}$ rich $\mathrm{M}_{23} \mathrm{C}_{6}$ carbides were found at grain boundaries as result of the $\mathrm{MC}$ degeneration. The $\mathrm{M}_{23} \mathrm{C}_{6}$ carbides

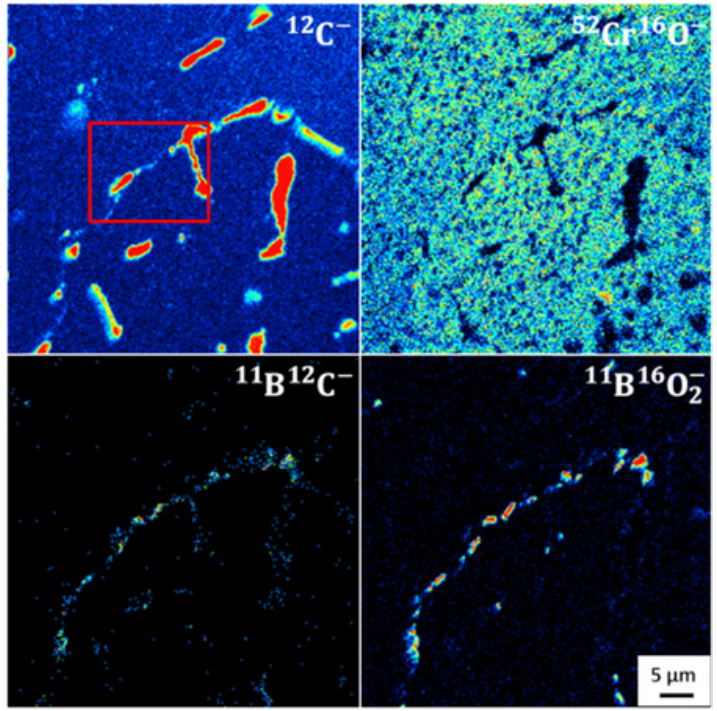

Figure 7. NanoSIMS images showing segregation of $\mathrm{B}$ and $\mathrm{C}$ at grain boundaries in a fully heat treated LB specimen, prior to creep test.

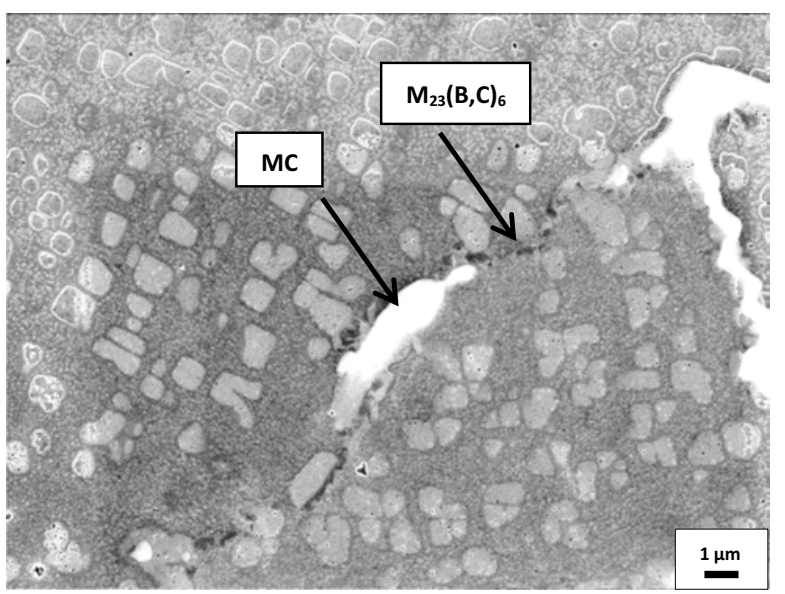

Figure 8. SEM image showing part of the analysed area by NanoSIMS of the LB specimen, see the labelled area in Fig. 8.

are the most abundant in nickel-based superalloys with high chromium content and form from the decomposition of $\mathrm{MC}$ carbides, either during heat treatment processes or prolonged service exposures. The dominant carbide reaction is $\mathrm{MC}+\gamma \rightarrow \mathrm{M}_{23} \mathrm{C}_{6}+\gamma^{\prime}$, where the $\mathrm{MC}$ carbides serve as source of carbon and chromium is depleted from the matrix to form the $\mathrm{Cr}_{23} \mathrm{C}_{6}$. In addition, it was observed that $\mathrm{B}$ can substitute for $\mathrm{C}$ in $\mathrm{M}_{23} \mathrm{C}_{6}$ resulting in $\mathrm{Cr}_{23}(\mathrm{~B}, \mathrm{C})_{6}$ carbides at grain boundaries, which is consistent with previous work $[4,10]$.

\subsection{Creep behaviour}

The creep curves measured for the three distinct chemical compositions are given in Fig. 10, it is seen that the minor additions of boron dramatically improve the creep resistance of STAL15-CC.

In particular, both low and high boron content specimens performed similarly, in terms of rupture time. Consistent with the creep strengthening implied by the 


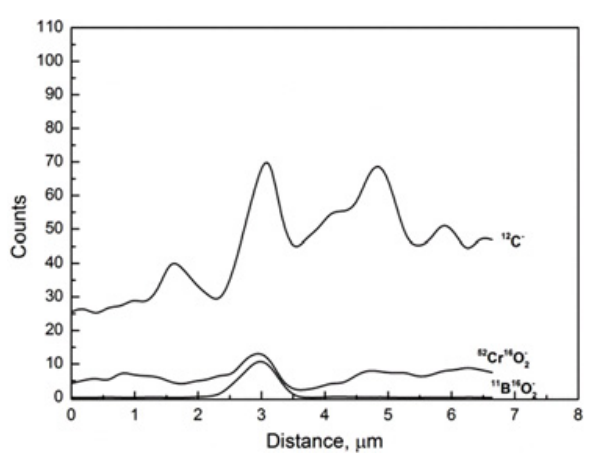

Figure 9. Line-scan across the grain boundary labelled in the SIMS analysis of HB specimen, see Fig. 5.

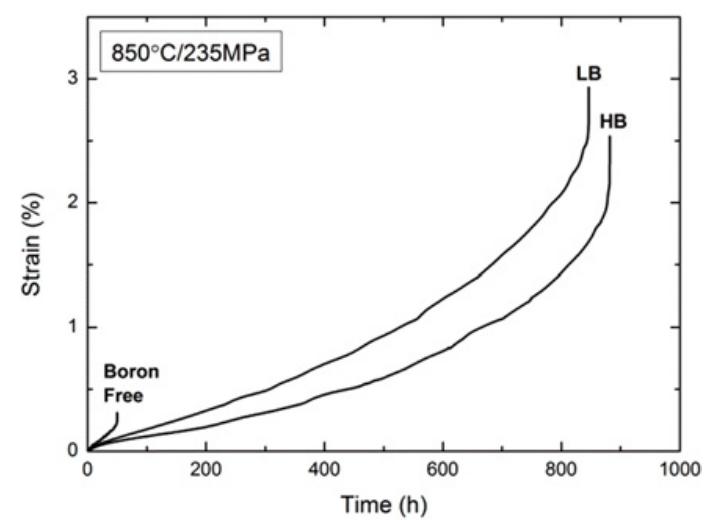

Figure 10. Creep strain vs. times curves for STAL15-CC at $850^{\circ} \mathrm{C}-235 \mathrm{MPa}$.

data in Fig. 10, transverse grain boundaries act as crack initiation sites with evidence of grain boundary oxidation being prevalent at and close to the specimen surfaces.

\section{Discussion \& rationalisation of results}

\subsection{The formation of $\gamma^{\prime}$ layers}

During the design of new polycrystalline superalloys, it becomes apparent the necessity of having a thorough understanding of the relationship between grain boundary character and mechanical properties. In particular, the contribution of grain boundary elements, such boron, to the carbide reactions taking place at the grain boundaries can play a pivotal role on the performance of conventional casting superalloys.

The occurrence of B-rich carbides at the grain boundaries can be rationalised by the higher mobility of boron in the $\gamma$ matrix than that of carbon. As a consequence higher amounts of boron diffuse from the $\gamma$ matrix towards the growing $\mathrm{M}_{23} \mathrm{C}_{6}$ carbide [11]. Yan [12] has suggested that the segregation of boron to the grain boundaries can facilitate the formation of $\gamma^{\prime}$ layers along the grain boundaries, in terms of interface energy. The presence of boron in the $\mathrm{M}_{23} \mathrm{C}_{6}$ results in the increase of the lattice misfit of $\mathrm{M}_{23} \mathrm{C}_{6} / \gamma$ and $\mathrm{M}_{23} \mathrm{C}_{6} / \gamma^{\prime}$ interfaces.

As a consequence, higher interfacial energies, $\sigma_{M 23 C 6 / \gamma}$ and $\sigma_{M 23 C 6 / \gamma^{\prime}}$, are achieved. In order to compensate the increase of the overall interfacial energy, the interface

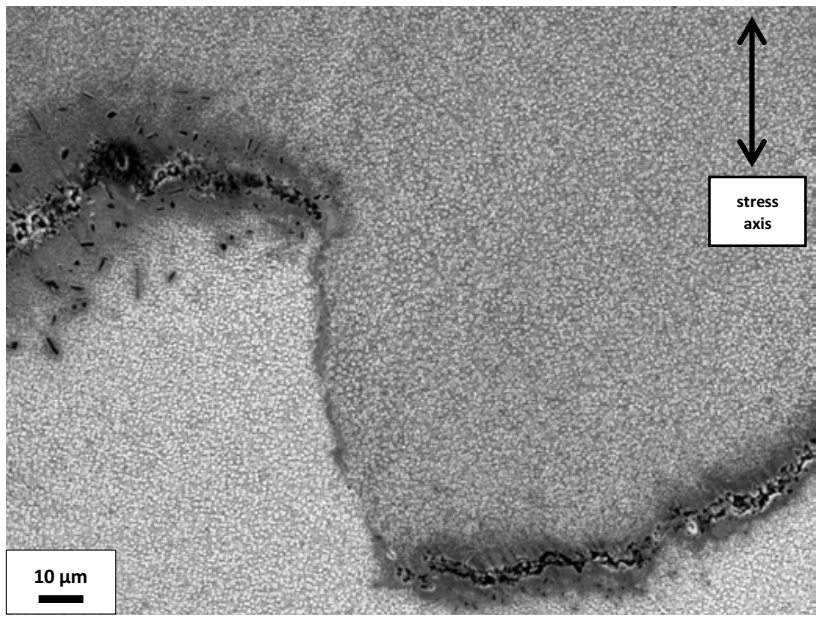

Figure 11. Oxidized cracked grain boundaries transverse to the applied stress axis.

area between the $\gamma$ and the $\gamma^{\prime}$ around the $\mathrm{M}_{23} \mathrm{C}_{6}$ carbide needs to decrease. Therefore, in terms of interface energy it is suggested that minor amounts of boron can facilitate the formation of continuous $\gamma^{\prime}$ layers along the grain boundaries. This is consistent with microstructural observations in this study. Relatively larger $\gamma^{\prime}$ precipitates were found at the grain boundaries of the LB specimen (Fig. 3), compared to those observed in the boron free specimen (Fig. 2). Further increase of the amount of boron results in continuous $\gamma^{\prime}$ layers along the grain boundaries (HB specimen - Fig. 4).

The precipitation of $\gamma^{\prime}$ layers, exerts a beneficial effect on the grain boundary character of STAL15-CC. The occurrence of these layers at the grain boundaries can suppress the diffusion of chromium from the matrix towards the grain boundary. Thereby, undesirable continuous films of $\mathrm{M}_{23} \mathrm{C}_{6}$ are avoided at the grain boundaries. At the same time, the occurrence of secondary $\gamma^{\prime}$ denuded zones in the vicinity of grain boundaries is minimized. It is known that areas depleted of chromium can be created close to grain boundaries due to the diffusion of chromium from the matrix towards the grain boundaries in order for Cr-rich carbides to form there. Thereby, the solubility for nickel and aluminium increases locally causing $\gamma^{\prime}$ to disappear.

\subsection{The effect of $\gamma^{\prime}$ layers on the creep resistance}

An interesting observation lies on the relatively lower strain rate of the high boron specimen. The above observation can be ascribed to the presence of $\gamma^{\prime}$ layers in the microstructure, prior to the creep test. It is well known that carbides can serve as crack initiation sites at the grain boundaries. However, the complex microstructure of brittle carbides enveloped within the ductile $\gamma^{\prime}$ envelopes can accommodate controlled slip at elevated temperatures, resulting in lower strain rates.

Moreover, it was observed that the presence of $\gamma^{\prime}$ layers at grain boundaries can enhance the fracture resistance of the alloy. In particular, microstructural 


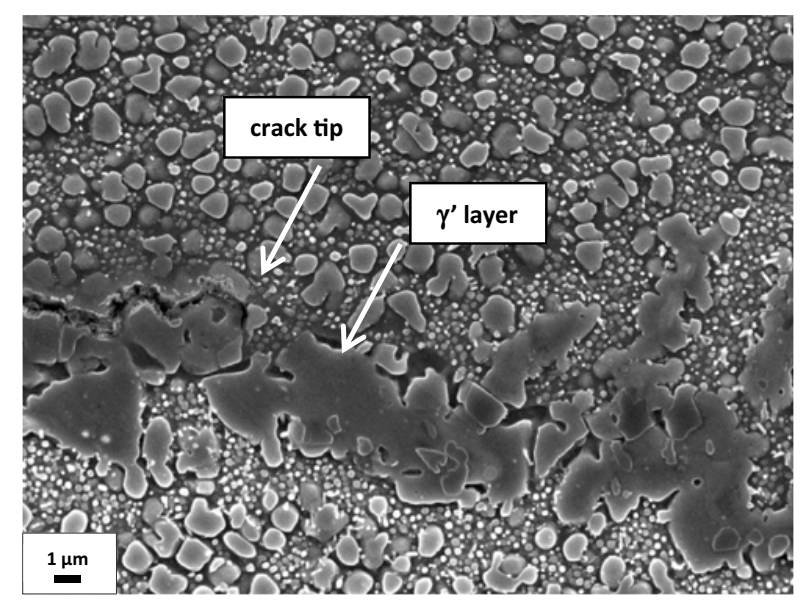

Figure 12. $\gamma^{\prime}$ layers impede crack propagation at grain boundaries.

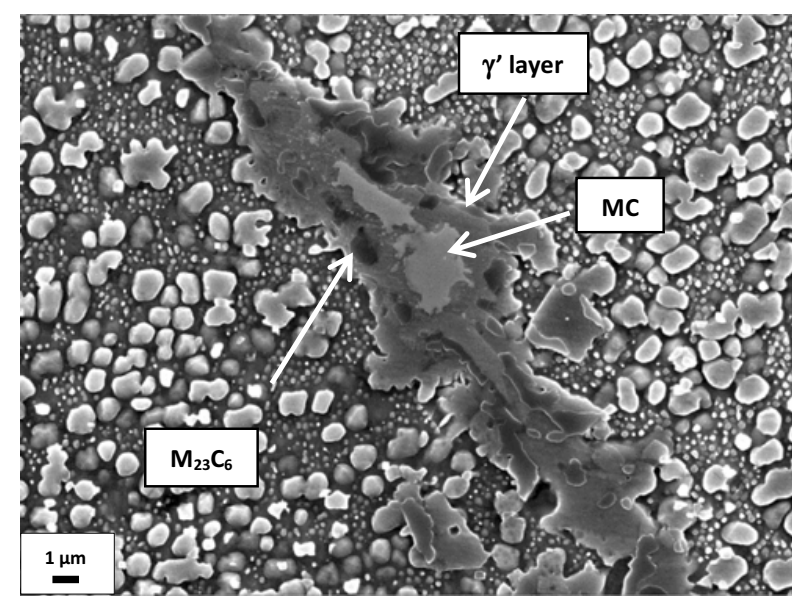

Figure 13. $\gamma^{\prime}$ layers precipitate at the grain boundaries of the low boron specimen after the creep test.

observations of the crept samples have shown that $\gamma^{\prime}$ envelopes serve as obstacles to crack propagation, which is consistent with literature. In Fig. 12 a characteristic example of the above observation is given, where the propagation of the crack tip is impeded by intergranular $\gamma^{\prime}$ layers.

However, microstructural observations of the crept low boron specimen revealed that $\gamma^{\prime}$ layers precipitate at the grain boundaries, where $\mathrm{MC}$ and $\mathrm{M}_{23} \mathrm{C}_{6}$ carbides are enveloped, as illustrated in Fig. 13. The formation of $\gamma^{\prime}$ layers due to $\mathrm{MC}$ decomposition at $850^{\circ} \mathrm{C}$ results in similar creep rupture time to high boron specimen. However, the precipitation of the $\gamma^{\prime}$ layers in the low boron specimen was not continuous along the grain boundaries. Grain boundaries decorated with primary $\mathrm{M}_{23} \mathrm{C}_{6}$ from the heat treatment process and the complex microstructure of $\gamma^{\prime}, \mathrm{MC}$ and $\mathrm{M}_{23} \mathrm{C}_{6}$ were observed. It is suggested that the discontinuous character of the $\gamma^{\prime}$ layer can be ascribed to the lower content of boron in the microstructure. Furthermore, the primary brittle $\mathrm{M}_{23} \mathrm{C}_{6}$ carbides were found to serve as crack initiation sites at grain boundaries, as illustrated in Fig. 14, whereas the enveloped $\mathrm{M}_{23} \mathrm{C}_{6}$ within the $\gamma^{\prime}$ layer serve as obstacle to crack propagation.

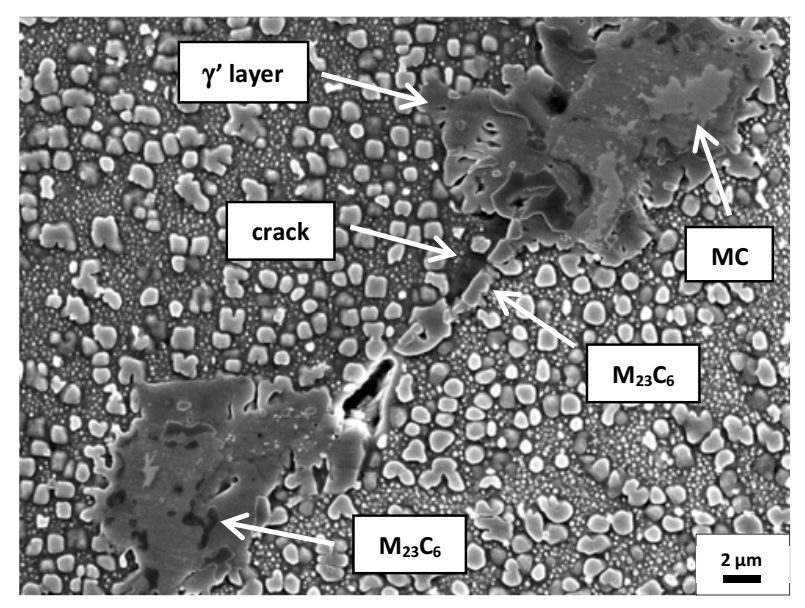

Figure 14. Primary $M_{23} C_{6}$ serving as crack initiation sites at grain boundaries in the low boron specimen.

\section{Conclusions}

Creep tests at $850{ }^{\circ} \mathrm{C}-235 \mathrm{MPa}$ were performed on a prototype nickel-based polycrystalline superalloy containing various amounts of boron. The following conclusions can be drawn from this work:

- The absence of boron in the microstructure results in continuous films of $\mathrm{M}_{23} \mathrm{C}_{6}$ type carbides at grain boundaries of fully heat treated specimens. As boron content increases, small discrete $\mathrm{M}_{23} \mathrm{C}_{6}$ carbides precipitate along the grain boundaries.

- It is shown that NanoSIMS can be used to distinguish between grain boundary phases in this system, i.e. between $\mathrm{M}_{23}(\mathrm{~B}, \mathrm{C})_{6}$ and $\mathrm{MC}$. There is a significant substitution of $\mathrm{B}$ for $\mathrm{C}$ in $\mathrm{M}_{23}(\mathrm{~B}, \mathrm{C})_{6}$.

- It is suggested that $\gamma^{\prime}$ layers form around Brich $\mathrm{M}_{23} \mathrm{C}_{6}$ during heat treatment processes and prolonged exposures at high temperatures.

- The presence of the ductile $\gamma^{\prime}$ layers at the grain boundaries can improve the creep ductility, by surrounding the brittle $\mathrm{MC}$ and $\mathrm{M}_{23} \mathrm{C}_{6}$ carbides which can serve as crack initiation sites.

- It is demonstrated that $\gamma^{\prime}$ envelopes at grain boundaries serve as obstacles to crack propagation, thus improving the fracture resistance at high temperatures.

The authors thank Siemens Industrial Turbomachinery, Sweden for the provision of funding and Doncasters plc. for casting STAL-15CC.

\section{References}

[1] T.J. Garosshen, T.D. Tillman, G.P. McCarthy, Met. Trans. A, 18, 69-77 (1987)

[2] L. Xiao, D.L. Chen, M.C. Chaturvedi, Superalloys 2004, 275-281 (2204)

[3] R.F. Decker, J.W. Freeman, Trans. AIME, 218 (1960) 
[4] M.A. Burke, J.J. Greggi, G.A. Whitlow, Scripta Met., 18, 91-94 (1984)

[5] C.L. White, J.H. Schneibel, R.A. Padgett, Met. Trans. A, 14, 595-610 (1983)

[6] M. McLean, A. Strang, Metals Technology, 14, 454 (1984)

[7] H.C. Chang, J.N. Grant, J. of Metals, 8, 544-551 (1956)

[8] W.C. Hagel, C.T. Sims, N.S. Stoloff, Superalloys II (1987)
[9] S.S. Yardley, K.L. Moore, N. Ni, J.F. Wei, S. Lyon, M. Preuss, S. Lozano-Perez, C.R.M. Grovenor, J. of Nuclear Materials, 443, 436-443 (2013)

[10] K.M. Delargy, G.D.W. Smith, Met. Trans. A, 14, 1771-1783 (1983)

[11] D. Tytko, P. Choi, J. Klöwer, A. Kostka, G. Inden, D. Raabe, Acta Mat., 60, 1731-1740 (2012)

[12] B.C. Yan, J. Zhang, L.H. Lou, Mat. Sci. Eng. A, 474, 39-47 (2008) 